\title{
COVID-19 Second Wave-The Tsunami and the Collapsing Indian Health Care Scene. Is Bevacizumab Strong Enough to Hold Fort
}

\author{
Sumant Gupta ${ }^{1}$ Neha Gupta ${ }^{2}$ Faran Naim² Arvind Minz ${ }^{3}$ \\ 1Department of Medical Oncology, Sarvodaya Cancer Institute, \\ Faridabad, Haryana, India \\ 2Department of Oncology, Sarvodaya Cancer Institute, Faridabad, \\ Haryana, India \\ ${ }^{3}$ Department of Internal Medicine, Sarvodaya Cancer Institute, \\ Faridabad, Haryana, India
}

\section{South Asian J Cancer 2021;10:48.}

COVID-19 or Coronavirus disease 2019 is a worldwide ongoing pandemic devastating the whole world, and we are at present facing the second wave which is hitting us like a tsunami. ${ }^{1}$ Although 90 percent of patients recover with home isolation but less than 10 percent of patients are afflicted with severe dyspnea caused by inflammatory pulmonary effusion or edema, leading to severe COVID-19, which further instigates pulmonary and systemic hypoxia. ${ }^{2,3}$

Bevacizumab has been used in clinical oncotherapy since 2004, with considerable reliability and safety. Taken together, we designed this trial to investigate the clinical benefits of bevacizumab plus standard care for treating patients with severe COVID-19.

In a recent article in Nature, bevacizumab's role has been extrapolated in severe COVID-19. Acute respiratory distress syndrome (ARDS) supposedly creates hypoxia in lung tissues. Bevacizumab, through its vascular endothelial growth factor (VEGF) antibody expression, increases tissue permeability and reduces hypoxia. ${ }^{4}$ It is being used as a substitute for the scarcely available drug, tocilizumab, with proposed equal efficacy in a small phase III article from Bangladesh. ${ }^{5}$

Keeping these observations in mind, we retrospectively analyzed our 28 patients being treated on bevacizumab during the last 2 months to see the impact of COVID-19pandemic on these patients, and assess the severity of the disease. The patients were called over the telephone to ascertain their well-being. A simple questionnaire was distributed to determine whether they had COVID, and if yes, whether they had hospitalization/ICU care or whether any patient succumbed to the disease.

On evaluation, out of the 28 patients interviewed, only 6 had COVID-19 infection, 4 had home isolation and were more or less asymptomatic, and 2 were admitted in the ward or died.
Address for correspondence Neha Gupta, Department of Oncology, Sarvodaya Cancer Institute, Sector 8, Faridabad 121006, Haryana, India (e-mail: drnehaguptagarg@gmail.com).

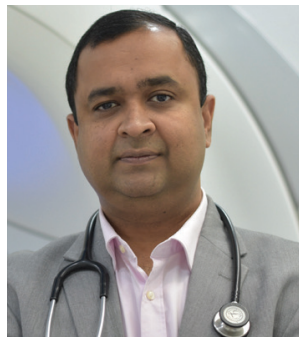

Dr Sumant Gupta

with mild disease. None of the patients had severe disease

Although the sample size is very small, and the hypothesis is premature, but it raises a pertinent question as to whether the drug also has a protective role in the pandemic!

COVID-19 or Coronavirus disease 2019 is a worldwide ongoing pandemic devastating the whole world, and we are at present facing the second wave which is hitting us like a tsunami. ${ }^{1}$ Although 90 percent of patients recover with home isolation but less than 10 percent of patients are afflicted with severe dyspnea caused by inflammatory pulmonary effusion or edema, leading to severe COVID-19, which further instigates pulmonary and systemic hypoxia. ${ }^{2,3}$

Conflict of Interest

None declared.

\section{References}

1 Parikh P. COVID-19 Pandemic: Contrast Between SAARC Countries and Western World. 2020. Available at: https:// www.m3india.in/contents/editor_pick/136721/covid-19-pandemic-contrast-between-saarc. Accessed on April 12, 2020

2 Bhatraju PK, Ghassemieh BJ, Nichols M, et al. Covid-19 in critically ill patients in the Seattle region - case series. N Engl J Med 2020;382(21):2012-2022

3 Huang C, Wang Y, Li X, et al. Clinical features of patients infected with 2019 novel coronavirus in Wuhan, China. Lancet 2020;395(10223):497-506

4 Jiaojiao Pang, Feng Xu. Efficacy and tolerability of bevacizumab in patients with severe Covid-19

5 Islam MA, Mazumder MA, Akhter N, et al. Extraordinary survival benefits of severe and critical patients with COVID-19 by immunemodulators: theoutcomeofaclinicaltrialinBangladesh. Euroasian J Hepatogastroenterol 2020;10(2):68-75 may not be used for commercial purposes, or adapted, remixed, transformed or built upon. (https://creativecommons.org/licenses/by-nc-nd/4.0/). 